were disappointed that one of the first protagonists of active management had not taken the opportunity to examine this question more closely. It would be interesting to compare fetal heart rate changes, scalp blood samples, incidence of caesarean section for fetal distress, condition of the fetus at birth, perinatal mortality, and the results of an early neurological and developmental assessment on all babies in a group of mothers and fetuses given oxytocin with a matched group before the policy of active management was instituted.

In the context of infection we were surprised that in 63 patients 24 hours were allowed to elapse after amniotomy before giving oxytocin, ${ }^{2}$ particularly as one baby was lost from infection in the induction of labour group.

We agree with Professor O'Driscoll that active management of labour is a logical extension of modern techniques, but we feel that the indications for intervention in labous might be better defined if the above data were available.-We are, etc.,

J. W. K. RITCHE R. O. ROBINSON Nuffield Institute for Medical Research, Oxford

1 Philpott, R. H., and Castle, W. M., Yournal of Combotrics and Gynealth, 1972, 79, 592

2 Patterson, w. M., foumal of Obstetrics and Gynaecology of

SIR,-The principle of the active management of labour referred to by Professor Kieran O'Driscoll and others (21 July, p. 135) is most welcome, but the authors are "preaching to the converted," especially to those of us who have worked in Cardiff in recent years. However, before it is accepted that very nearly all primigravidae at the National Maternity Hospital, Dublin, have labours lasting less than 12 hours, the evidence provided should be examined more closely. To begin with, how can one talk of the "active management of labour" in 34 women admitted for eleotive caesarean section? Furthermore, their only objective criterion for defining the onset of labour was the time of admission to the delivery unit. Hendricks et al., ${ }^{1}$ to whom the authors refer, detailed many more criteria for the onset of labour than merely the time of admission.

We later learn that 38 patients were transferred to an "antenatal" ward and not classed as "prolonged labour" simply because they were not retained in the delivery unit. Are the authors really saying that none of these patients were "in labour" in the antenatal wand? Then, with regard to the induction of labour, 204 patients were admitted "in labour" to the delivery unit, presumably from, the antenatal wards. Therefore, on their own admission, labour must have stanted in the antenatal ward, but readers would have been interested to know the degree of cervical dilatation when these patients were transferred; if, for example, some of these patients were nearly fully dilated, it is little wonder that "labour" lasted less than 12 hours in the delivery unit.

With regard to the authors' views on pain relief in labour, I would agree that it is an emotional subject, bur even six hours can be a long time for a woman in great pain, without any sedation.-I am, etc.,

West Wales General Hospital,

G. ROBERTS

Carmarthen

1 Hendricks, C. H., Brenner, W. B., and Kraus G., American Yournal of Obstetrics and Gynecology, 1970, 106, 1065.

\section{Xylose Test}

SIR,-The interesting article by Drs. G. E. Sladen and P. J. Kumar (28 July, p. 223), in which they criticize the D-xylose absorption test, deserves some comment. According to the authors the test is unable to separate patients with mucosal lesions from those without evidence of gut disease and therefore "serves little useful punoose in routine practice." They claim that it is the standard test for mucosal function and that it has been superseded by the technique of jejunal biopsy.

In our unit the test has been in constant use since 1958; however, not to the exclusion of other tests but always in conjunction with others such as estimations of faecal fat, nitrogen, volatile fatty acids, and certainly jejunal biopsy. The test is a function test and therefore should not be asked to give information about histological changes, just as the reverse applies to jejunal biopsies. Though the two usually run parallel there is ample evidence that not only-as Dr. Sladen and Kumar stress-may the xylose test be abnormal in patients with a histologically normal muoosa but abnormal histological changes may be found without any evidence of malabsonption. ${ }^{1}$ So neither test can be regarded as infallible.

It is not surprising that Drs. Sladen and Kumar were dissatisfied with the xylose absorption test and that they got a considerable overlap between normal control values and those from patients with mucosal changes. They used a dose of $25 \mathrm{~g}$ xylose and estimated the urinary excretion after only five hours. Butterworth et al. ${ }^{2}$ introduced the 5-g dose, which made the test more reliable, raising the mean of the urinary xylose excretion from $25 \%$ to $36 \%$, and Chanarin and Bennett ${ }^{3}$ showed that the $25-\mathrm{g}$ dose was too high, produced nausea and diarrhoea and therefore unreliable excretion rates.

Furthermore, in 1967 we confirmed the observation of Butterworth and showed that the consideration of the two-hour excretion value greatly increased the sensitivity of the test by demonstrating reduced excretion in some patients who had excreted normal amounts of xylose if only the five-hour value had been considered. ${ }^{4}$ Kendall ${ }^{5}$ confirmed the importance of using the two-hour value and stressed the importance of taking the age and renal status of the patients into consideration if meaningful results were to be obtained.

With these modifications and precaution the urinary excretion of xylose is a helpful diagnostic test for differentiating the malabsorption due to enteropathies from other types of malabsorption. For this purpose it should always be used in conjunction with ather function tests as well as with the histological extamination of the jejunal mucosa. It is invaluable on its own for monitoring the progress of the patient-for example, the response to gluten-free diet-or for assessing the sensitivity of the patient to gluten $^{6}$ or gluten fractions. ${ }^{7}$ It is a test that can be carried out with a minimum of inconvenience to the patient.-We are, etc.

\section{R. SCHNEIDER}

R. D. MONTGOMERY

H. G. SAMMONS

Metabolic Unit,

East Birmingham Hospital,

Birmingham

1 Rubin, C. E., Eidelman, S., and Weinstein, W. M., Gastroenterology, 1970, 58.409.

Butterworth, C. . E., jun., Perez-Santiago, E. Martinez de Jesus, J., and Santini, R., Ne England fournal of Medicine, 1959, 261, 157. Fournal, 1962, 1, 985 .

4 Sammons, H. G., et al., Gut, 1967, 8, 348.

Kendall, M. J., Nutter, S., and Hawkins, C. F. Lancet, 1972, 1, 667.
Kendall M. J., Cox,

endall M. J., Cox, P. S., Schneider, R., and Hawkins, C. F., Lancet, 1972, 2, 1065.

\section{Saccharin in the Balance}

SIR,-I should like to congratulate the writer of the splendid leading article on this subject (28 July, p. 185).

As a physician who has a large number of diabetic patients in my clinic I am appalled on what flimsy evidence cyclamates were withdrawn from general circulation. I am concerned that saccharin might suffer the same fate. I should like to suggest that the B.M.A. should make a very firm stand on this issue and prevent certain lobbies from distorting scientific facts (some of them pseudoscientific, such as dosing tiny animals with colossal doses of any drug) and then abolishing a very useful drug/chemical/ food.

If saccharin is removed from the market then I can only foresee a lot of trouble for diabetic patients. It is useless to go on at length and tell them that will-power alone will overcome their weight problems; one knows only too well that patients on chlorpropamide and tolbutamide do feel very hungry and commonly increase their weight. As one patient pointed out to me, doctors who have not undergone the problems themselves rarely know what they are talking about-at least where diabetes and weight gain are concerned.-I am, etc.,

Rotherham Hospital,
Rotherham, Yorks

K. D. BARDHAN

\section{Promotion of Research on Deafness}

Sir,-Mr. H. A. Beagley and his $10 \mathrm{co-}$ signatories (25 Augrust, p. 455), criticizing the report on deafness prepared by Dr. Annette Rawson and published by the Department, ${ }^{1}$ quote from $\mathrm{my}$ preface in a way which implies that I do not support what Dr. Rawson has said. It must surely be clear that the Department cannot be committed to everything contained in Dr. Rawson's report since this report was prepared as a source of information upon which the Medical Research Council was to advise the Secretary of State. Upon the main point of contention the M.R.C. has advised the Secretary of State that it would not be appropriate to establish a separate research institute of audiology.

I do not intend to answer the letter you have published in detail since I have promised to meet some of its authors for discussion. I write only to make it quite 